\title{
FEATURES OF THE IMPACT OF THE SOLAR WIND DIAMAGNETIC STRUCTURE ON EARTH'S MAGNETOSPHERE
}

\author{
V.A. Parkhomov \\ Baikal State University, \\ Irkutsk, Russia,pekines_41@mail.ru \\ N.L. Borodkova \\ Institute of Space Research RAS, \\ Moscow, Russia,nlbor@mail.ru \\ V.G. Eselevich \\ Institute of Solar-Terrestrial Physics SB RAS, \\ Irkutsk,Russia,esel@iszf.irk.ru
}

\author{
M.V. Eselevich \\ Institute of Solar-Terrestrial Physics SB RAS, \\ Irkutsk,Russia,mesel@iszf.irk.ru \\ A.V. Dmitriev \\ Skobeltsyn Institute of Nuclear Physics, Moscow State University \\ Moscow, Russia,dalexav@mail.ru \\ V.E. Chilikin \\ Baikal State University, \\ Irkutsk,Russia,dfreez@yandex.ru
}

\begin{abstract}
In Earth's orbit on June 28, 1999, there was a diamagnetic structure (DS) representing a filament with a uniquely high speed (about $900 \mathrm{~km} / \mathrm{s}$ ). We show that the filament is a part of the specific sporadic solar wind (SW) stream, which is characterized as a small interplanetary transient. We report the results of studies on the interaction between such a fast filament (DS) and Earth's magnetosphere. Around noon hours at daytime cusp latitudes, we recorded a powerful aurora in the UV band (shock aurora), which rapidly spread to the west and east. Ground-based observations of geomagnetic field variations, auroral absorption, and auroras on the midnight meridian have shown the development of a powerful substorm-like disturbance (SLD)
\end{abstract}

( $A E \sim 1000 \mathrm{nT}$ ), whose origin is associated with the impact of the SW diamagnetic structure on the magnetosphere. The geostationary satellite GOES-8, which was in the midnight sector of the outer quasi-capture region during SLD, recorded variations of the $B_{z}$ and $B_{x}$ geomagnetic components corresponding to the dipolization process.

Keywords: streamer, filament, diamagnetic structure; dayside auroras, shock aurora, substorm-like magnetospheric disturbance.

\section{INTRODUCTION}

Diamagnetic structures (DS) form a basis for the slow quasi-stationary solar wind (SW) in Earth's orbit. Their sources on the Sun are the streamer belt [Svalgaard et al., 1974], streamer chains [Eselevich et al., 1999; Eselevich et al., 2007] or pseudostreamers [Wang et al., 2007]. These structures in fact represent magnetic flux tubes (in general, magnetic flux ropes) with plasma [EselevichV.G., Eselevich M.V., 2005]. On their surface there is a diamagnetic current decreasing the magnetic field inside the flux tube and increasing it outside the tube. Diamagnetic flux tubes hold their angular size when moving from the Sun to Earth, i.e. they are quasistatic along the entire path [Eselevich V.G., Eselevich M.V., 2005].

The sporadic SW driven by coronal mass ejections (CMEs) is recorded in Earth's orbit as a sequence of shock waves, shock-heated plasma, and magnetic cloud, or interplanetary coronal mass ejection (ICME). Inside the magnetic cloud, we can often see a curved thin magnetic flux rope with a denser plasma, which is a filament (or eruptive prominence) ejected from the Sun's surface. It is also a DS with the same properties as in the magnetic flux tube [Eselevich V.G., Eselevich M.V, 2005].

The analysis of two events [Parkhomov et al., 2015] of collision between a filament and Earth's magnetosphere has shown that this interaction causes a short- term (20-40 min) activation of substorm-like magnetospheric processes. They begin in the dayside magnetosphere with a burst of auroras in the noon sector (shock aurora) [Zhou, Tsurutani, 1999]. Note that the shock aurora arises not only in the interaction between the magnetosphere and interplanetary shocks, but also during abrupt and large rises in SW proton pressure [Borodkova, 2010]. We examine only the interactions of the magnetosphere with SW diamagnetic structures, determined from the negative correlation coefficient between SW density jumps and interplanetary magnetic field (IMF) modulus with the preceding long-term positive or weakly negative IMF $B_{z}$ component. In such cases, after the shock aurora on the noon side, leading fronts of auroras spread to morning and evening sectors of the auroral zone. Three-five minutes after the shock aurora on the dayside in the magnetotail and on Earth there occurred phenomena characteristic of substorm events: bursts of Pi1-2 oscillations, enhancement of electron and proton fluxes in the geostationary orbit, and auroral electrojet (the AE index increases to $600 \mathrm{nT}$ ). Duration of the disturbance depends on the time of the DS-magnetosphere interaction. We call such disturbances substorm-like (SLD) as in [Huttunen et al., 2002].

Differences between the SLDs we consider and classical substorms and pseudobreakups of various types lie in a well-determined energy source - SW DS, duration of the phenomenon, and its onset on the dayside. Intro- 
ducing the new definition, we take into account that substorm-like events, which do not develop into a fullscale substorm [Akasofu, 1971], are called pseudobreakups. However, this term has been used to describe many similar phenomena in subsequent studies [Zhou, Tsurutani, 2001].

The purpose of this work is to study evolution of highlatitude disturbances, other than a classical substorm (i.e. substorm-like), under the influence of SW diamagnetic structures on the magnetosphere, through the example of a unique event occurring on June 28, 1999.

\section{ANALYSIS OF SOLAR OBSERVATIONS AND MEASUREMENTS OF SOLAR WIND PARAMETERS IN EARTH'S ORBIT FOR JUNE 28, 1999}

Let us examine structural features of the SW stream that interacted with the magnetosphere on June 28, 1999 between 03:30 and 05:12 UT. Figure 1 shows variations in density, velocity, and temperature of SW protons and in the IMF modulus as derived from Wind satellite data for June 25-28, 1999. This Figure indicates that a sequence of three interplanetary shocks was recorded in the SW stream before the interval of interest. The first shock occurred on June 26, 1999 at $~ 03: 20$ UT; the second, on June 26, 1999 at $\sim 20: 00 \mathrm{UT}$; and the third, on June 28, 1999 at $\sim 2: 30$ UT. They corresponded to three storm sudden commencements (SSC): 1) June 26, 1999 at 03:25 UT; 2) June 26, 1999 at 20:08 UT; 3) June 26, 1999 at 02:49 UT. These shocks were caused respectively by the following halo CMEs (propagating in a direction close to the Sun-Earth line): 1) CME on June 23, 1999 at 07:31 UT (solar coordinates N23E42); 2) CME on June 24, 1999 at $13: 31$ UT (coordinates N29W13); 3) CME on June 26, 1999 at $~ 07: 31$ UT (coordinates N25E00).

The specific sporadic SW stream observed between 03:30 UT and 04:48 UT on June 28, 1999 (Figure 2) can be characterized as a small interplanetary transient (SIT). In fact, SIT is ICME of small size (usually ICME lasts much longer, for 0.5-1.5 days). According to [Rouillard et al., 2011], in Earth's orbit, SIT has the following features:

1) 1-10 hr decrease or increase in the polar (latitudinal) angle $\theta$ of the magnetic field $B$ (Figure 2, $e$ );

2 ) rapid decrease in the parameter $\beta=8 \pi P / B^{2}(\beta$ is the ratio of plasma thermal pressure to magnetic pressure) to $<<1$ (Figure $2, g$ ), associated with a sharp increase in $B$ and a decrease in $N_{\mathrm{p}}$ at the SIT boundary (Figure 2, $a, b$ ).

SIT generally propagates in the slow quasistationary SW whose velocity in Earth's orbit $V_{\mathrm{sw}} \leq$ (400-450) km/s. In this case, the back of SIT often exhibits a peak of $N_{\mathrm{p}}$ whose profile anticorrelates with the magnetic field profile $B$.

Such a structure of SW plasma density profiles and IMF modulus is diamagnetic. According to [Rouillard et al., 2011], SIT with a diamagnetic structure near the Sun is caused by eruption of the helmet top of the streamer footpoint (or the top of the streamer arch structure). When moving, the $N_{\mathrm{p}}$ peak in the back of the transient may increase due to SIT compression by the overtaking fast quasi-stationary SW stream [Rouillard et al., 2011].

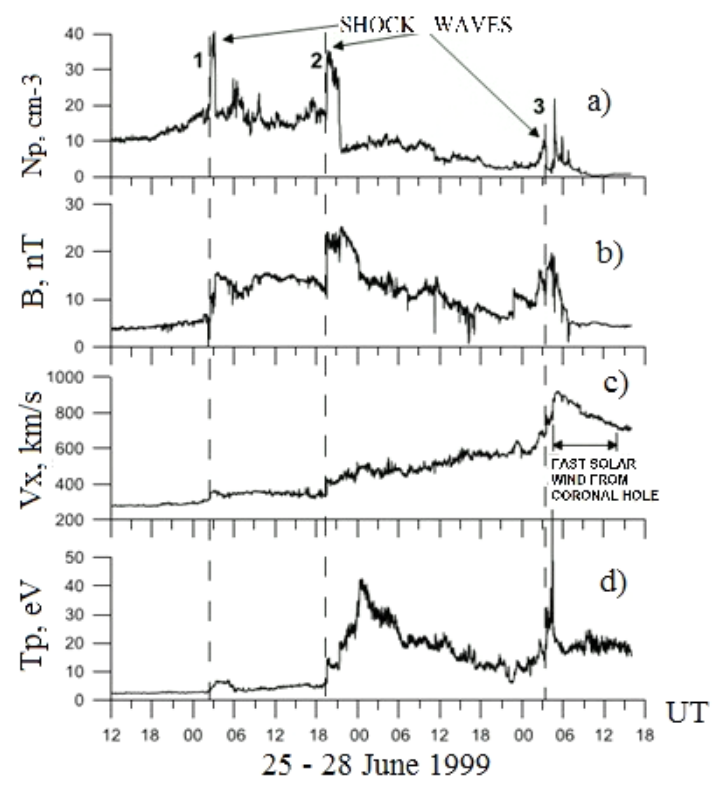

Figure 1. Variations in SW and IMF parameters on June 25-28, 1999, as derived from Wind satellite data [http:// cdaweb.gsfc.nasa.gov/cgi-bin/eval2.cgi]: proton density (a); IMF modulus $(b)$; velocity along the Sun-Earth line $(c)$; proton temperature $(d)$. Along the X-axis, time in hours starts at 12:00 UT on June 25, 1999

Figure 2 shows that the event occurring on June 28, 1999 between 03:30 and 04:48 UT (vertical dashed lines) satisfies the above requirements. But it has a very important feature: this SIT propagated in the quasistationary fast $\mathrm{SW}$ with $V_{\mathrm{sw}} \approx 600 \mathrm{~km} / \mathrm{s}$. The fast $\mathrm{SW}$ originated from a coronal hole $(\mathrm{CH})$, whose center crossed the central meridian on June 25, 1999. This conclusion follows from the calculation (G.V. Rudenko [http://bdm.iszf. irk.ru]) of the coronal magnetic field from the measured photospheric magnetic field (Figure 3 ). The calculated positions of the footpoint of the open magnetic flux tube of this $\mathrm{CH}$ are marked with arrows in Figure 3. Referring to Figure 3, $b$, the center of gravity of the calculated footpoint of the $\mathrm{CH}$ magnetic flux tube crossed the central meridian on June 25, 1999 between 0 and $14 \mathrm{UT}$ at a latitude $\theta_{0} \approx 25^{\circ}$. The estimated area of the tube footpoint in Figure 3, $b, S \approx 5.5 \cdot 10^{10} \mathrm{~km}^{2}$. This allows us to determine the maximum velocity $V_{\mathrm{M}}$ of the fast SW stream from this $\mathrm{CH}$ at a distance of $1 \mathrm{AU}$ with the formula [Eselevich et al., 2009]

$$
V_{\mathrm{M}}\left(S, \theta_{0}\right)=\left\{\left(2.25 \cdot 10^{-9} S+500\right)-4\left(\left|\theta_{0}-B_{0}\right|\right)\right\},
$$

where $B_{0}$ is Earth's heliolatitude, $S$ is the area of the footpoint of the $\mathrm{CH}$ magnetic flux tube (in $\mathrm{km}^{2}$ ). Then, from the relation

$$
t_{\mathrm{M}}\left(V_{\mathrm{M}}\right)=t_{0}+236.5 R_{0} / V_{\mathrm{M}},
$$

where $R_{0}$ is the solar radius, we find the time $t_{\mathrm{M}}$ of arrival of the SW stream from this $\mathrm{CH}$ [Eselevich et al., 2009].

The estimate yields $V_{\mathrm{M}} \approx 590 \mathrm{~km} / \mathrm{s}, t_{\mathrm{M}} \approx 07-21$ UT for June 28, 1999. $V_{\mathrm{M}}$ agrees with the observed velocity of the fast SW from this $\mathrm{CH}$ in the early hours of June 28, 1999, and the estimated $t_{\mathrm{M}}$ corresponds to the observed one up to \pm 12 hr [Eselevich et al., 2009]. 


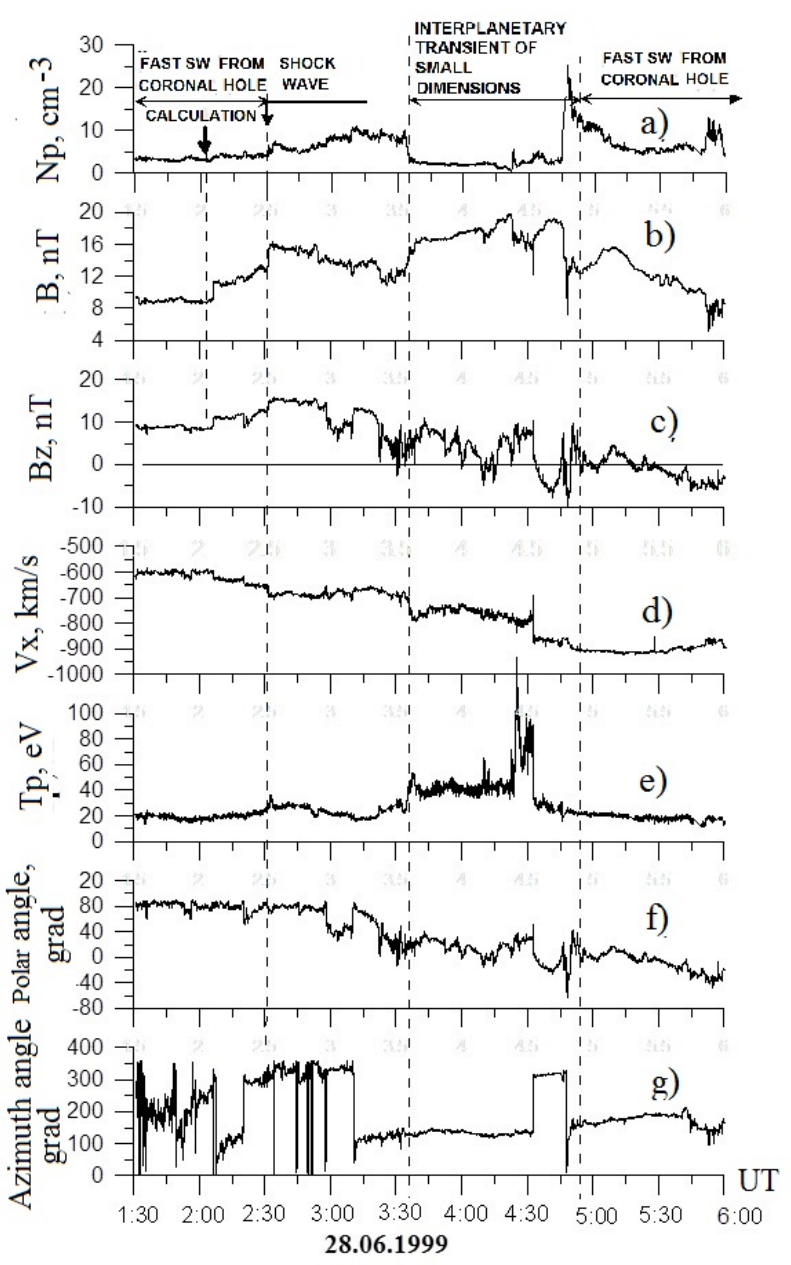

Figure 2. Variations in SW and IMF parameters on June 28, 1999, as derived from Wind satellite data: proton density (a); IMF modulus $(b)$; velocity along the Sun-Earth line $(c)$; proton temperature $(d)$; IMF polar angle (in the heliocentric coordinate system, it is measured from the solar equator, the positive direction is to the north along the Z-axis) (e); IMF azimuth angle (measured from the $\mathrm{X}$-axis directed along the Earth-Sun line, along the antisunward Y-axis) $(f)$; plasma parameter $\beta(g)$. Along the $X$-axis, time in hours starts at 01:30 UT on June 28, 1999

At the same time, as can be seen in Figures 1 and 2, after $\sim 5$ UT on June 28, 1999, immediately after SIT, the velocity of the fast SW from the $\mathrm{CH}$ under study increases. This is the quasi-stationary SW from $\mathrm{CH}$ as evidenced by the relatively low proton density $N_{\mathrm{p}}<10 \mathrm{~cm}^{-3}$ and the characteristic value of the magnetic field $B \approx 4-5 \mathrm{nT}$ (in the interval of at least 06:30-18:00 UT on June 28, 1999, in Figure 1) at a maximum velocity $V_{\mathrm{M}} \approx 900 \mathrm{~km} / \mathrm{s}$. The only difference is the duration of the stream (arrows in Figure 1, c), $\Delta t \approx 12 \mathrm{UT}$, while the typical $\Delta t$ for fast streams with $V_{\mathrm{M}} \approx 600-900 \mathrm{~km} / \mathrm{s}$ is from 3 to 5 days.

Such an increase in $V_{M}$ can be explained if we assume that on June 25, 1999 the area $S$ of the footpoint of the $\mathrm{CH}$ magnetic flux tube after crossing the central meridian increased about 3 times within several hours. In this case, according to formula (1), the velocity of the fast SW from this hole must have increased to $~ 850$ $\mathrm{km} / \mathrm{s}$. Such an increase in $S$ is quite possible, since on June 24-25, 1999 the area of this $\mathrm{CH}$ changed (it in- creased more than 2 times, see Figure 3, $a, b$ ).

So, the uniqueness of this event is that the halo CME, which emerged on June 26, 1999 at $~ 07: 31$ UT (coordinates N25E00) and occurred with prominence eruption, was affected by the fast SW whose speed reached an extremely high value - almost $900 \mathrm{~km} / \mathrm{s}$. The process is as follows. According to [http://cdaw.gsfc.nasa.gov/ CME_list], at $R \approx 20 R_{0}$ the halo CME had a velocity $V_{\perp}=400 \mathrm{~km} / \mathrm{s}$ in the plane of the sky; at the same time it slowed down with acceleration $a=-9.8 \mathrm{~m} / \mathrm{sec}^{2}$.

This means that its velocity in the radial direction was, as evidenced by [Schwenn et al., 2005], at most $V_{\mathrm{r}} \approx 1.8 V_{\perp} \approx 720 \mathrm{~km} / \mathrm{s}$ and, moreover, continuously decreased due to CME deceleration when moving to Earth.

However, if on June 25, 1999 for several hours the area of the footpoint of the $\mathrm{CH}$ magnetic flux tube after crossing the central meridian increased approximately

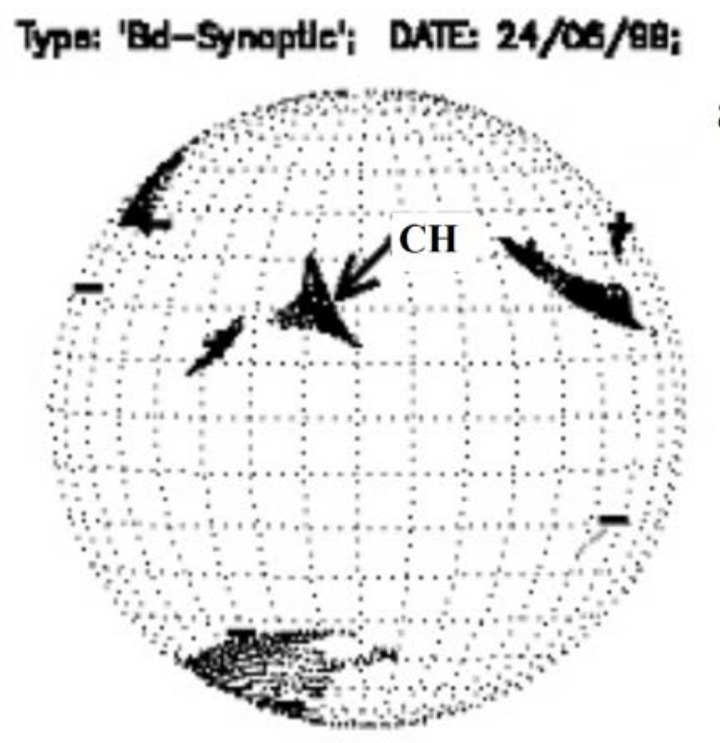

Type: 'Bd-Synoptle'; DATE: 25/06/8B;

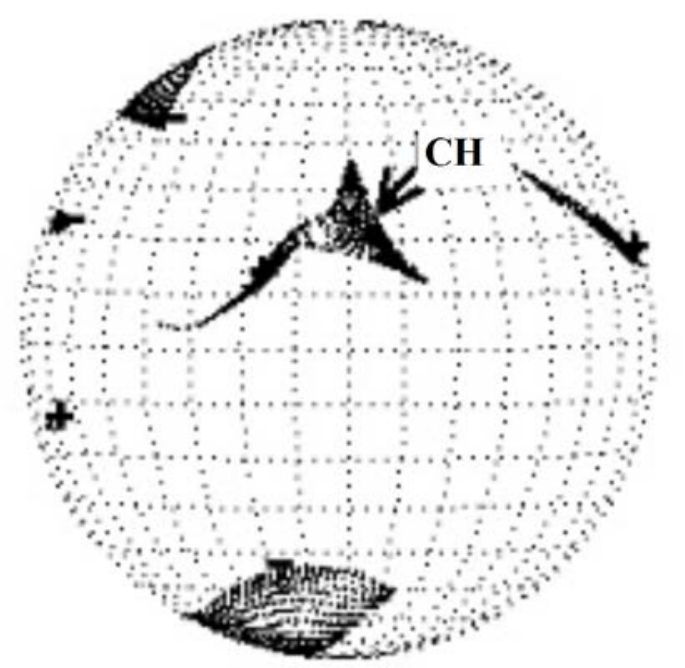

b

Figure 3. Positions of footpoints of open magnetic flux tubes corresponding to coronal holes, calculated in the potential approximation [http: //bdm.iszf. irk.ru]: for 14:28 UT on June 24, 1999 (a); for 14:28 UT on June 25, $1999(b)$. Plus is the direction of the magnetic field from the Sun; minus, to the Sun 
threefold, the velocity of the fast SW from this $\mathrm{CH}$ might have increased to $\sim 900 \mathrm{~km} / \mathrm{s}$. As a consequence, the CME along with the DS (filament), which decelerated and had a relatively low speed, was overtaken and carried away by the fast SW; then it was recorded in Earth's orbit in the form of an interplanetary transient with small dimensions moving at $V \approx 900 \mathrm{~km} / \mathrm{s}$.

\section{MAGNETOSPHERIC RESPONSE TO DS ON JUNE 28, 1999}

\subsection{Analysis of SW observations before the magnetopause and in the geostationary orbit}

The DS front in Earth's orbit was registered by three satellites (Figure 4, $a$, Table 1). The delay between the arrival of the DS front at the Geotail and Interball-1 satellites is $7 \mathrm{~min}$. This delay was caused by the inclination of the front to the Earth-Sun line with the normal $n$ $=(-0.55,-0.54,0.64)$ in the solar ecliptic coordinate system. The normal to the DS front was determined from the following considerations. Knowing coordinates of satellites when a disturbance is passing through them and times of detection of the front of the disturbance with instruments onboard these satellites and assuming that the front is flat and propagates with SW velocity, we can determine its propagation direction. To use this method, at least three satellites must be in SW. The accuracy of this method is low (20-30\%). As indicated by the direction of the normal, the first contact with the magnetosphere occurred on the dusk-noon side, and probably therefore the response was registered earlier in the geostationary orbit than by Interball-1 and IMP-8. In terms of the 1 min interval of discretization of data from satellite magnetometers, the advance was $2 \mathrm{~min}$ for GOES- 8 and 3 min for GOES-10 (up to $\pm 0.5 \mathrm{~min}$ ) with respect to the beginning of registration of the SW proton flux jump aboard Interball-1, which was ahead of the near-Earth shock front (Figure 4, $a$ ).

Note features of geomagnetic variations for the geostationary satellite GOES-8, which was in the outer quasi-capture region in the midnight meridian (Figure $4, b$ ), essential for interpreting a disturbance type.

The magnetometer of the satellite recorded characteristic variations in the $B_{z}$ and $B_{x}$ components (Figure $4, c$ ). The moments of the beginning of intervals of antiphase $B_{z}$ and $B_{x}$ variations are marked with rectangles II (05:25-05:27), III (05:31-05:38) in Figure 4, $c$.

Table 1

Coordinates of GSE satellites for June 28, 1999 at 05:12 UT

\begin{tabular}{|l|c|c|c|}
\hline \multicolumn{1}{|c|}{ Satellite } & $x_{\mathrm{GSE}}, \mathrm{km}$ & $y_{\mathrm{GSE}}, \mathrm{km}$ & $z_{\mathrm{GSE}}, \mathrm{km}$ \\
\hline ACE & $1.49560 \cdot 10^{6}$ & 250542 & -29671.6 \\
\hline Wind & $1.3351 \cdot 10^{6}$ & $-1.4355 \cdot 10^{5}$ & -16365 \\
\hline Geotail & 72253 & $1.7019 \cdot 10^{5}$ & 3003 \\
\hline IMP-8 & 197838 & -111795 & -116679 \\
\hline Interball-1 & 143194 & -99865 & -41207 \\
\hline GOES-8 & -38699 & -2568 & 16567 \\
\hline GOES-10 & -20629 & 35179 & 10716 \\
\hline Polar & 15576 & -43143 & 16316 \\
\hline
\end{tabular}

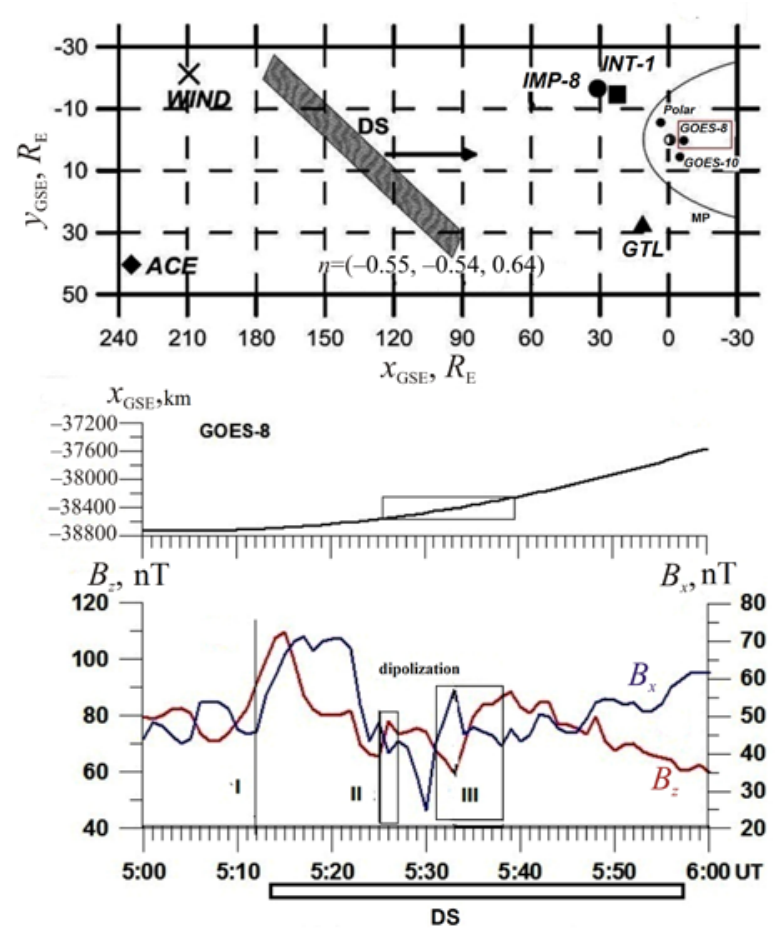

Figure 4. Leading DS front, position of satellites in SW and inside the magnetosphere $(a)$; GOES-8 satellite trajectory in the outer quasi-capture region in the midnight meridian $(b)$, the rectangle indicates the dipolization interval. Variations in the $B_{z}$ and $B_{x}$ components from GOES-8 data $(c)$ : $\mathrm{I}$ is the beginning of the intensification of the glow in the noon meridian; II, III are the moments of the beginning of antiphase variations in $B_{z}, B_{x}$ in the geostationary orbit (dipolization intervals)

These antiphase variations in $B_{X}$ and $B_{z}$ can be interpreted as manifestation of the dipolization effect of the geomagnetic field, which is an indispensable attribute of a substorm [Lui, 2001]. A peculiarity of the event under study is that the dipolization occurred not at the beginning, but in the active phase of the substorm-like disturbance.

\subsection{Features of the global magnetospheric response}

The SW stream, whose structure is described in Introduction, caused a magnetospheric response having several features that distinguish it from the commonly observed magnetospheric disturbances driven by SW sporadic structures. Features of the global magnetospheric response are illustrated in Figure 5.

On June 25-28, 1999, there were three weak magnetic storms (rectangles I, II, III) with sudden commencements (1, 2, 3 in Figure 5) [http://www.obsebre.es/en/rapid].

The storms are classified as weak according to the $K_{\mathrm{p}}$ index total for June $26-28\left(\Sigma K_{\mathrm{p}}=26-\right.$ and $26+$ respectively). SSC of the first storm was recorded on June 26, 1999 at 03:25 UT with maximum $D s t=-15$ nT at $\sim 12$ UT on June 26, 1999. SSC of the second storm occurred at $\sim 20: 15$ UT on June 26, 1999 with maximum $D s t=-22$ nT at $\sim 23$ UT on June 27, 1999. This storm had three powerful substorms with $A E_{\max }=1350 \mathrm{nT}$ at 18:28 UT. 


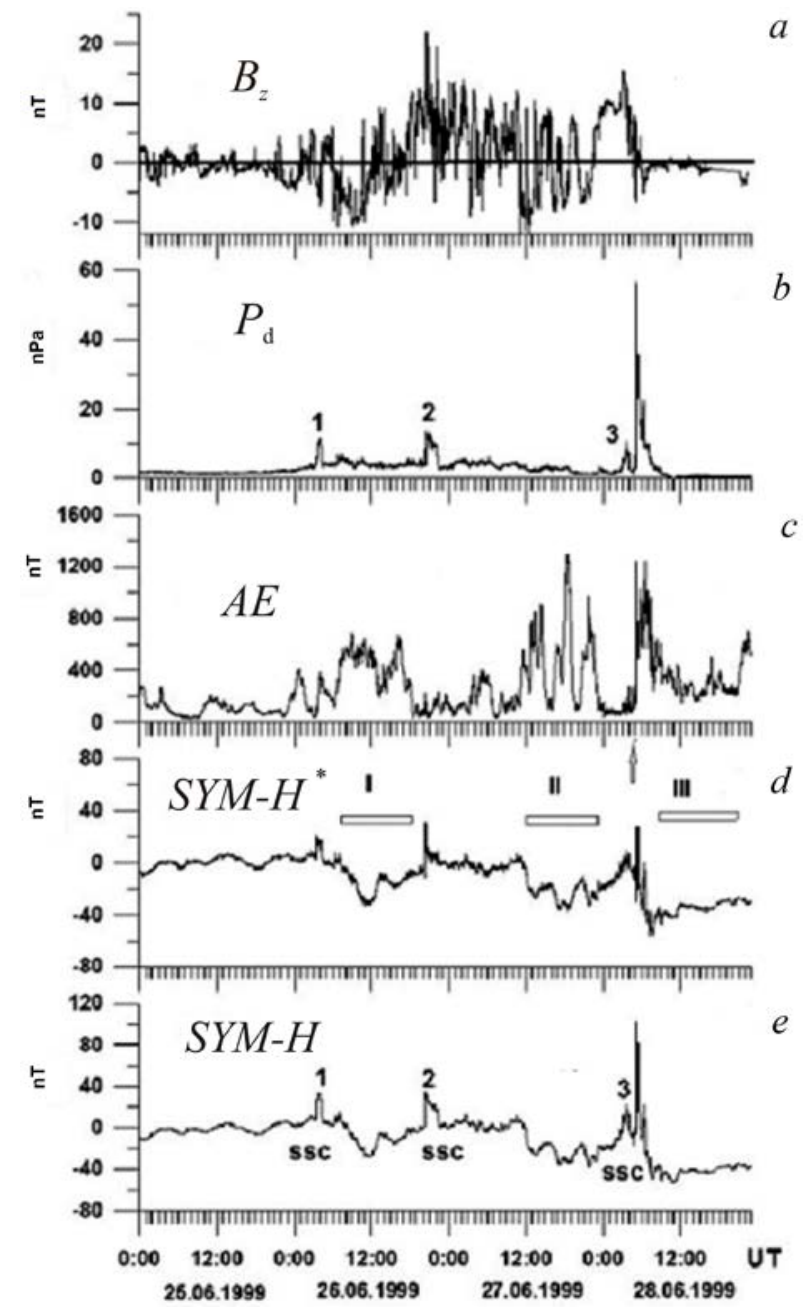

Figure 5. Variations in IMF $B_{z}(a)$, SW pressure $(b)$, geomagnetic indices $A E(c), S Y M-H^{*}(d)$, and $S Y M-H(e)$. The arrow indicates the beginning of SLD and the subsequent storm induced by DS. Rectangles I, II, III denote intervals of weak magnetic storms.

The geomagnetic field returned to the undisturbed level in the early hours of June 28, $1999\left(K_{\mathrm{p} 0-3}=2\right)$. The third SSC is not marked in the catalog [http://www.obsebre.es/en/rapid]. However, the analysis of magnetograms from observatories, which are used to determine SSC in the catalog, has shown that at 02:49 UT there was a $\sim 3$ min jump of the $H$ component with a maximum value of $\sim 21 \mathrm{nT}$ at the observatories of the daytime sector (Alibag, Kakioka, Honolulu). After the SSC, surface currents increased and the $S Y M-H$ index reached $25 \mathrm{nT}$; at 04:00 UT, the $S Y M-H$ index sharply dropped, reflecting the amplification of the ring current similar to the amplification in the storm main phases (up to $-18 \mathrm{nT}$ ).

In the subsequent three-hour interval, magnetic activity increased sharply $\left(K_{\mathrm{p} 3-6}=6+\right)$. The increase in geomagnetic activity in this interval is associated with the effect of the SW diamagnetic structure on the magnetopause, in contrast to the three previous increases caused by interplanetary shock waves. The global network Intermagnet at 05:09 UT recorded a global sharp increase in the $H$ component. Observatories of the daytime sector, whose data are used to determine the SYM- $H$ and
Dst indices, registered positive sharp increases in the $H$ component up to $110 \mathrm{nT}$ within one minute. But this disturbance in the catalog is not classified as SSC. In general, according to the combination of morphological features, disturbance III can be classed as a weak magnetic storm with SSC at 02:49 UT. At the beginning of the storm main phase, there was a sharp increase in geomagnetic activity due to the DS-magnetosphere interaction. During this storm at 11 UT on June 28, 1999, Dst was maximum among these three storms (-41 nT). Given the large pressure jump at 05:12 UT and following the results obtained in [O’Brien, McPherron, 2002], from the $S Y M-H$ variation we excluded the contribution of surface currents amplified by magnetosphere compression at the magnetopause:

$$
S I M-H^{*}=S I M-H-10\left(\sqrt{P_{\mathrm{d}}}-1.5\right) \text {. }
$$

The comparison of the SYM- $H$ variations with the corrected variation (Figure $5, d, e$ ) shows that the pressure jump in DS occurred at the beginning of the main phase of the third magnetic storm.

The SW proton density jump at 05:09 UT caused a powerful magnetospheric disturbance - dayside and nightside auroras, global amplification of ionospheric currents and magnetic activity with maximum values of the $A E$ index of $1262 \mathrm{nT}$ at 05:13 UT and $1033 \mathrm{nT}$ at 05:37 UT. It is very important that the SW proton density variation within 05:09-05:55 UT is anticorrelated with the IMF modulus:

$$
R\left(B, N_{\mathrm{p}}\right)=-0.8 \pm 0.1 \text {. }
$$

This SW structure is diamagnetic [Parkhomov et al., 2015].

The magnetospheric disturbance in the interval 05:12-06:00 UT is very similar in its manifestations to the substorm [Akasofu, 1971]. However, it began on the dayside, without preliminary phase of energy accumulation in the magnetotail (the IMF vertical component had been oriented to the north for 5 hours before DS arrival); the duration of the disturbance depends on the size of DS in Earth's orbit. As already mentioned in Introduction, such a complex of phenomena caused by interaction between the magnetosphere and the SW diamagnetic structure is called a substorm-like disturbance.

It is important to note that in the interval June 2528, 1999 under study, storms (and substorms as their constituents) occurred at different preceding orientations of the IMF vertical component: first and second storms with predominantly southward $B_{z}$. During the DS-magnetosphere interaction, $B_{z}$ was positive.

We should emphasize that before the disturbance, the IMF vertical component was directed to the north for $\sim 5$ hrs before the interaction with DS $\left(B_{\text {zav }}=5.29 \pm 4.21 \mathrm{nT}\right)$. The southward $B_{z}$ component was recorded for a short time in intervals 04:59-05 10 UT $\left(B_{z}\right.$ av $\left.=-4.54 \pm 1.67 \mathrm{nT}\right)$ and 05:10-05:12 UT $\left(B_{\mathrm{zav}}=-\right.$ $3.8 \pm 3.4 \mathrm{nT}$ ); then the vertical component was again consistently northward, varying within $0-8 \mathrm{nT}$. We believe that the amount of energy released in the SLD cannot have been accumulated in the magnetotail for 10 minutes the southward $B_{z}$ component existed. 

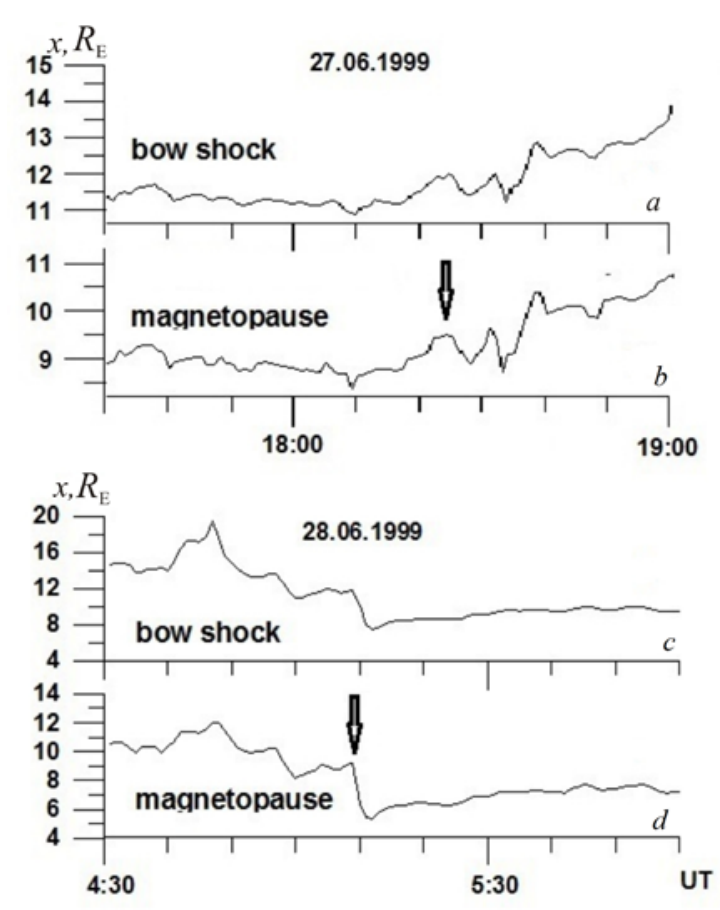

Figure 6. Variations in the position of the bow shock boundary and the magnetopause ( $x$ coordinate): bow shock (according to [http://cdaweb.sci.gsfc.nasa.gov/cdaweb/ istppublic]) (a), magnetopause calculated by the model [Lin et al., 2010] for June 27, 1999 (b); the same for June 28, 1999 (c, d). Arrows indicate onsets of the substorm and SLD

Particularly noteworthy are variations in the position of the shock front and magnetopause (Figure 6), which are synchronous with variations in the proton density and SW dynamic pressure. The position of the magnetopause is calculated by the model developed in [Lin et al., 2010], and the position of the bow shock is taken from [http://cdaweb.sci.gsfc.nasa.gov/cdaweb/istp_public].

In interval II (Figure 5) during powerful substorms, the boundary of the magnetosphere moves away from Earth when SW proton density falls, and the maximum of the substorm intensity is observed against the expanding magnetosphere (Figure 6, $a, b$ ). Conversely, SLD in interval III (Figure 5) begins after the proton density jump and, accordingly, after the magnetosphere compression (Figure 6, $c, d$ ).

The above facts allow us to make a preliminary conclusion that the two magnetospheric disturbances had different energy sources comparable in the $A E$ index. Since in interval II before the substorm, which began on June 27, 1999 at 17:20 UT (Figure 5), the $B_{z}$ component was predominantly southward for about $4 \mathrm{hrs}$, we can assume that the energy source of this substorm $\left(A_{\max }=1350 \mathrm{nT}\right)$ was the energy accumulated in the magnetotail due to reconnection of IMF and magnetospheric field lines [Lui, 2001].

As in interval III (Figure 5) before the onset of SLD the $B_{z}$ component was northward for $\sim 5$ hrs, the reconnection did not cause energy to be stored in the magnetotail. Before the SW pressure jump, jumps of all IMF components were recorded; therefore, we can suppose that the source of SLD is a strong compression of the magnetosphere by the SW diamagnetic structure and DS energy input to the magnetosphere.

\subsection{Analysis of the auroral response to DS from satellite auroral images and ground-based geomagnetic observations}

Let us perform a comparative analysis of auroral observations, auroral absorption, geomagnetic variations, and geomagnetic pulsations to find differences between classical substorms and SLDs.

June 27, 1999 substorm

The IMF vertical component in the interval 11:3024:00 UT was predominantly southward with three $20 \mathrm{~min}$ intervals when it was northward, and, as a consequence, there were three substorms in this interval. Consider in detail the substorm occurring at 17:20-19:10 UT (Figure 7, $a-c)$. The substorm develops according to the well-known scenario, and differences from SLD are manifested themselves in the development of the substorm initial phase, particularly in the dynamics of auroras in the UVI range (we have used Polar satellite observations). Satellite images of auroras were taken using LBHL and LBHS filters [Torr et al., 1995]. Figure 7, $a-c$ presents: $B_{z}$ variations ( $a$ ); a fragment of the magnetogram ( $H$ component) from the Barrow Observatory (BRW, geographic coordinates $71.32^{\circ}$ $\mathrm{N}, 203.38^{\circ} \mathrm{E}$ ) of the night sector and moments of $\mathrm{Pi} 2$ observation at middle latitudes (arrows) (b); satellite images of auroras with the LBHS filter $(c)$.

In the interval of interest, there is a classical substorm in auroras, which begins with intensification of brightness of the quiescent arc near the midnight meridian (17:24:17 UT frame in Figure 7, c) [Akasofu, 1971]. After the breakup, the arc of auroras moves to the west, and in the recovery phase, the auroras move to the east. It can be seen here that the auroras in longitude cover the area from 23 to 06 MLT in the latitude interval $58^{\circ}-72^{\circ} \mathrm{N}$.

Along with the substorm in auroras, a substorm occurs in auroral absorption [http://aurora.phys.ucalgary.ca/ cgibin/rio]. The absorption starts at 17:30 UT and reaches a maximum value of $1.5 \mathrm{~dB}$ at 18:30 UT at Fort Churchill Observatory (not shown).

The Barrow Magnetic Observatory, located in the morning sector (05 MLT), records a negative bay-like disturbance of the $H$ component with a maximum amplitude of $860 \mathrm{nT}$ (Figure 7, b). The mid-latitude station Mondy in the midnight sector records bursts of Pi2 oscillations. Thus, all the data shown in Figure 7, $a-c$ suggest that the June 27, 1999 magnetospheric disturbance is an auroral substorm. It is important that the substorm develops when the magnetopause and bow shock move away from Earth (Figure 6, $a, b$ ).

Substorm-like disturbance on June 28, 1999

Unlike the substorm we have analyzed, the source of SLD is a strong magnetosphere compression by the SW structure we identified as DS. The main feature of this structure [Parkhomov et al., 2015] is a high negative correlation coefficient between $B$ and $N_{\mathrm{p}}$. In the event we analyze, $R\left(B, N_{\mathrm{p}}\right)=-0.8 \pm 0.1$. Note once more that before the disturbance began, before the DS-magnetosphere interaction, $B_{z}$ was northward for $\sim 5$ hrs. Southward turnings of $B_{z}$ near the magnetopause (Figure $4, a$ ) are recorded by satellites (IMP-8, Geotail, Interball-1) from 04:59 to 05:10 UT, and then the vertical component is again steadily northward. 


\section{Aurora dynamics}

The main features of the auroral magnetosphere response to DS are the appearance of an intense glow in the UVI range on the noon side at polar cusp latitudes and the rapid spread of the glow to the night side (Figure $8, b$, LBHL filter). Images captured with the LBHS filter (Figure 8, c) clearly show the aurora dynamics.

The auroras that occur in the daytime polar cusp upon interaction of the magnetosphere with interplanetary shocks and SW high-pressure regions are called shock aurora and have been discussed in many papers [Zhou, Tsurutani, 1999, 2001; Zhou et al., 2009]. We examine the interaction not with a shock wave, but with DS.

The peculiarity of the event under study and its dif- ference from the shock aurora lies in the fact that a slight increase in the aurora at latitudes $\sim 73-78^{\circ}$ in the near-noon sector 11-13 MLT begins at 05:00:07 UT at the moment of IMF $B_{z}$ reversal from north to south. But a sharp increase in the aurora brigtness occurs at 05:11:46 UT - at the moment of SW proton density jump and northward turning of $B_{z}$. Therefore, in the event of interest we cannot discount the role of reconnection in the energy transfer from SW to the magnetosphere. But we should emphasize once again that the lifetime of the southward $B_{z}$ component was $\sim 10 \mathrm{~min}$, while classical works on substorms suggest that the substorm onset is preceded by 1 hr existence of southward $B_{z}$, which determines the growth phase.
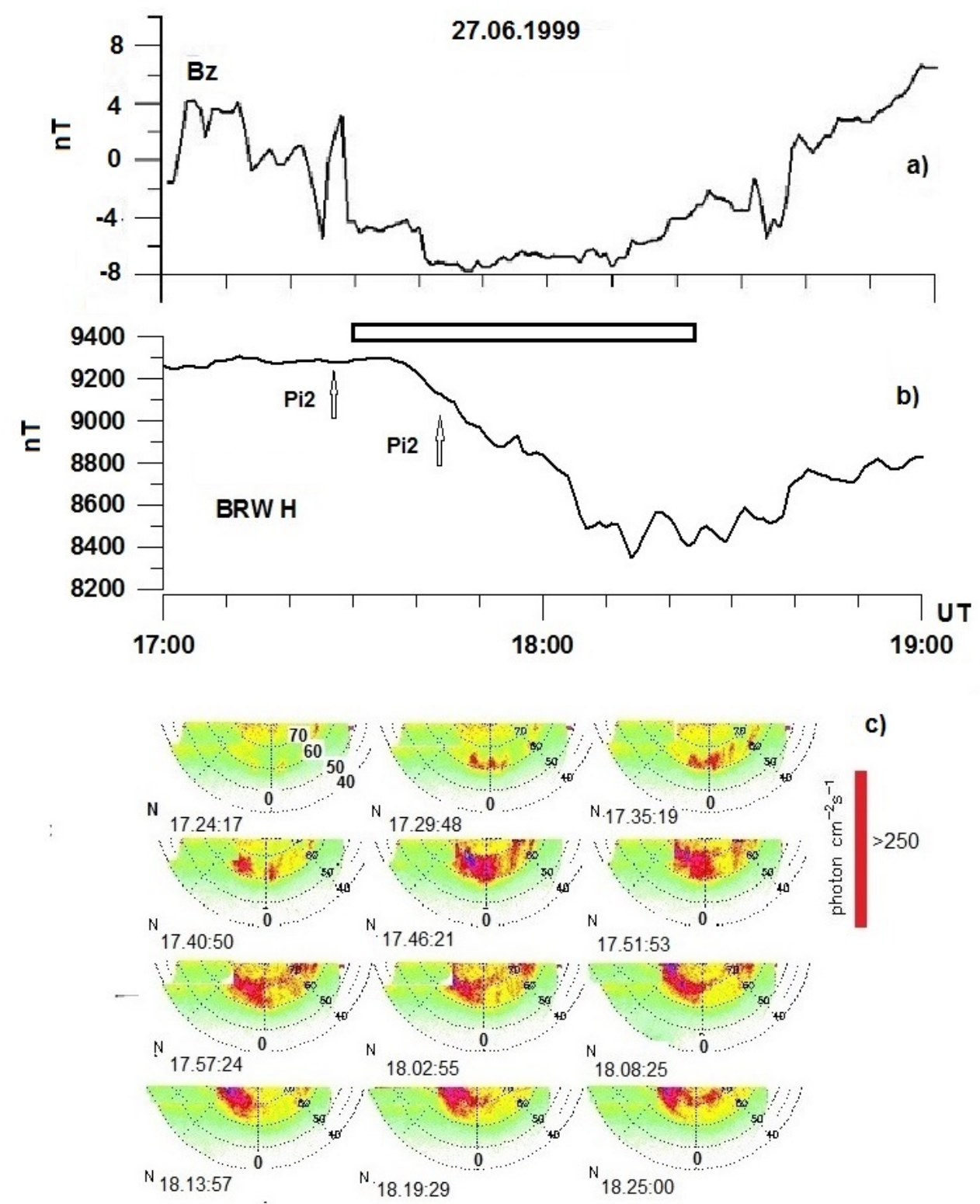

Figure 7. Sequence of development of a classical auroral substorm: IMF $B_{z}$ variations $(a)$; $H$ component variations $(b)$ at the Barrow Observatory. The rectangle indicates the time when Polar satellite observed auroras. Arrows denote moments of recording of Pi2 oscillations at the mid-latitude station Mondy. Panel $a$ shows auroral images from the Polar satellite (LBHS filter) 

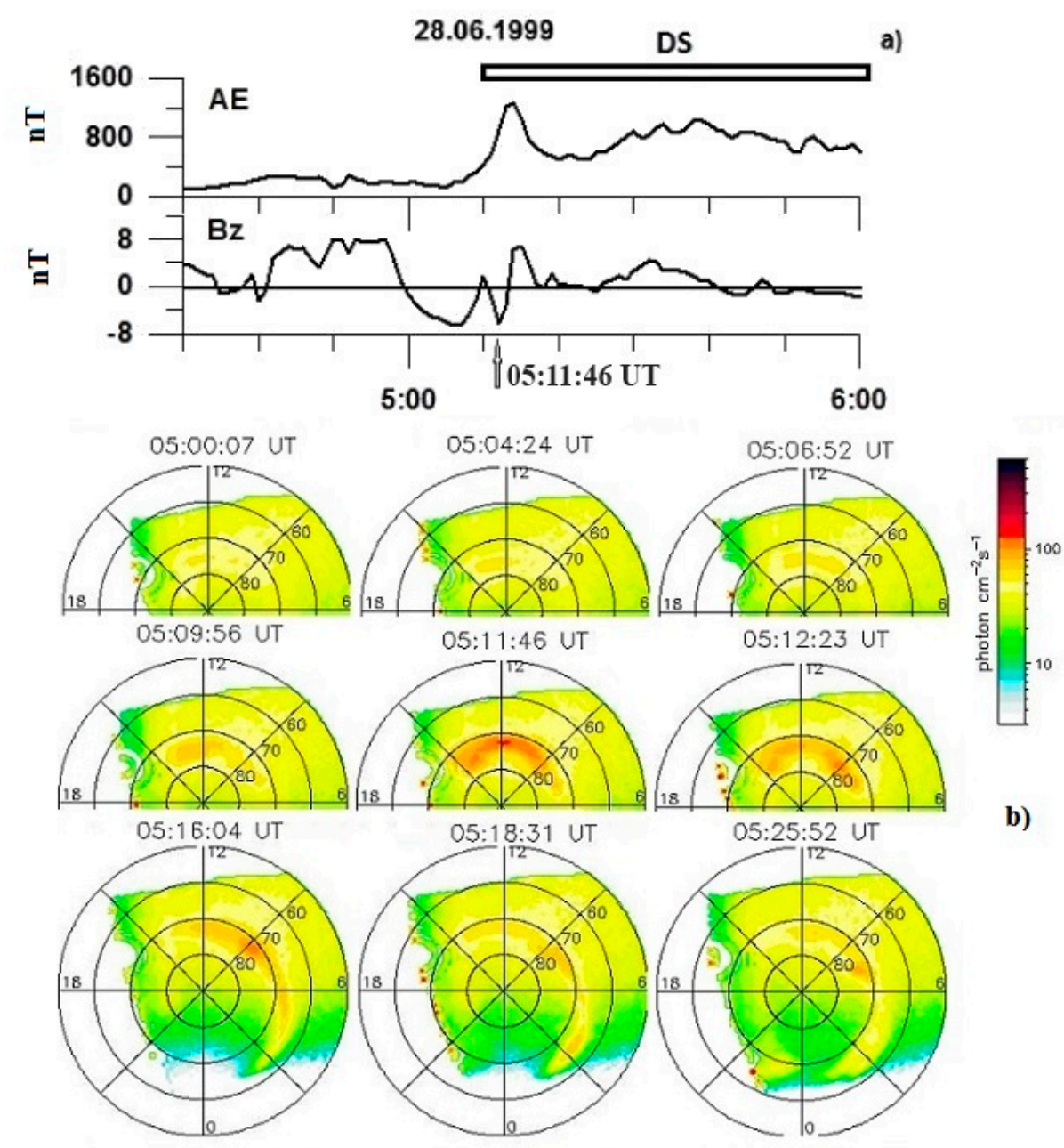

))

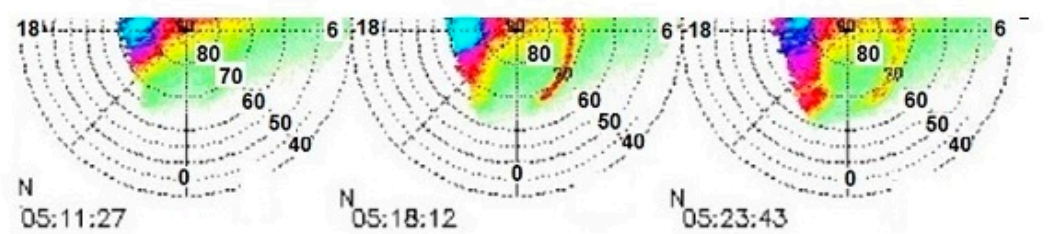

c)
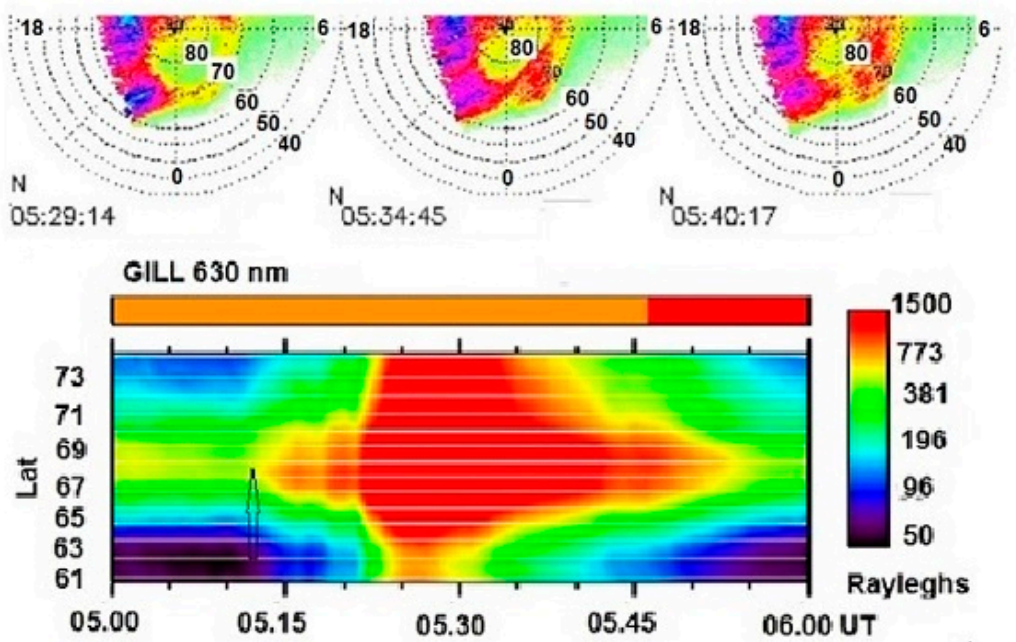

d)

Figure 8. Sequence of SLD development after the magnetosphere-DS interaction: variations in the $A E$ index and IMF $B_{Z}$ component, the rectangle denotes the DS observation time $(a)$; sequence of aurora images from the Polar satellite with LBHL (b) and LBHS (c) filters; data from a ground-based zenith photometer near the midnight meridian, MLT $\sim 23^{\mathrm{hr}}$ (Gillam station) $(d)$, the arrow indicates the beginning of the intensification of the aurora brightness in the noon meridian 
Table 2

\begin{tabular}{|c|l|l|c|c|}
\hline № & \multicolumn{1}{|c|}{ Station Name } & Abbreviation & Geographic latitude & Geographical longitude \\
\hline 1 & Pinava & PINA & $50.20^{\circ}$ & $263.96^{\circ}$ \\
\hline 2 & Island lake & ISLL & $53.86^{\circ}$ & $265.34^{\circ}$ \\
\hline 3 & Gillam & GILL & $56.38^{\circ}$ & $265.36^{\circ}$ \\
\hline 4 & Fort Churchill & FCHU & $58.76^{\circ}$ & $265.92^{\circ}$ \\
\hline 5 & Eskimo Point & ESKI & $61.11^{\circ}$ & $265.95^{\circ}$ \\
\hline 6 & Rankin Inlet & RANK & $62.82^{\circ}$ & $267.80^{\circ}$ \\
\hline 7 & Taloyk & TALO & $69.54^{\circ}$ & $266.45^{\circ}$ \\
\hline
\end{tabular}

We can assume that in the event under study the growth phase of SLD began with the reversal of the IMF vertical component and lasted for $10 \mathrm{~min}$.

Figure 8, $a$ shows variations in the $A E$ index of auroral geomagnetic activity and IMF $B_{z}$ component. The rectangle marks the DS observation time. It can be seen that before the magnetosphere-DS interaction the IMF vertical component had been southward for $10 \mathrm{~min}$. However, for such a short lifetime of the negative $B_{z}$ component the amount of energy that was then released in SLD cannot have flowed into the magnetosphere.

Let us consider the auroral dynamics. Successive frames (Figure 8, $b, c$ ) show that after the initial brightening at 05:00:07 UT at daytime polar cusp latitudes $\left(\sim 72^{\circ}-76^{\circ}\right)$ at $05: 11: 46$ UT the brightness near the noon meridian strongly increases and aurora fronts begin moving to morning and evening sides. The shift of the eastern edge of the glow is very distinctly seen in Figure 8, $b$ (05:16:04 UT frame), in which the glow front reached the pre-midnight sector $\left(\sim 02^{\mathrm{hr}}\right)$. Figure $8, c$ shows closing of aurora boundaries in the midnight meridian (05:18:12 UT frame) and that the glow covers the entire auroral oval (05:23:43 UT frame).

As derived from ground-based aurora observations made with zenith photometers in the midnight meridian (Gillam station, GILL), a sharp (tenfold) increase in the aurora intensity in the $486 \mathrm{~nm}$ line begins at a latitude of $67^{\circ}$ at $\sim 05: 14: 30 \mathrm{UT}$, i.e., $\sim 3 \mathrm{~min}$ after the sharp increase in auroras on the dayside (Figure $8, d$ ).

Zhou, Tsurutani [1999] have shown that the velocity of propagation of a leading shock aurora front to sunrise and sunset depends on the velocity of propagation of a shock along the magnetopause and amounts to 6-11 $\mathrm{km} / \mathrm{s}$. In the event of interest, the glow on the nightside begins $\sim 3$ min after the enhancement of the glow on the dayside. It is likely that such a little delay can be attributed to the high propagation velocity of DS in SW ( 900 $\mathrm{km} / \mathrm{s})$.

Dynamics of auroral absorption, electrojet and geomagnetic pulsations

Peculiarities of the development of the disturbance on the nightside of Earth are shown in Figure 9.

Here we present data from the meridional network CANOPUS (MLT 23-01 hr) with high temporal resolution (5 s sampling frequency) in a geomagnetic latitude range $61.15-79.65^{\circ}$ (geographical coordinates of the stations are listed in Table 2) from 04:40 to 06:00 UT: fragments of riometer records $(a)$ and magnetograms of the $H$ component $(b)$, as well as fragments of magnetograms filtered in the frequency range of Pi1 geomagnetic pulsations (10-45 s) (c). Vertical line 1 in
Figure 9, $a-c$ indicates the time of a sharp aurora enhancement in the UVI range (05:11:49 frame in Figure $8, b)$ in the noon meridian. The rectangle indicates the DS recording time. Arrows point to: the beginning of the negative bay in the $H$ component, the beginning of recording of maximum geomagnetic pulsations Pi1, and the beginning of the bay in auroral absorption at each station. All these phenomena constitute a substorm complex [Akasofu, 1971].

The sequence of the phenomena is as follows. 11 minutes after the sharp increase in the $H$ component caused by amplification of Chapman-Ferraro currents at the magnetopause and by magnetosphere compression, GOES-8, which was located in the outer quasi-capture region in the midnight meridian, records variations in the $B_{z}$ and $B_{x}$ geomagnetic components (Figure 9, $a-c$, rectangles 2,3 ), characteristic of the dipolization of the geomagnetic field - one of the main features of substorms [Sergeev et al., 2012; Lui, 2001].

At $05: 13 \mathrm{UT}$, the station ISSL $\left(\varphi=53.86^{\circ}\right)$ registers the beginning of the negative bay in auroral absorption. Absorption of this type is caused by precipitation of energetic electrons with energies $E=10-40 \mathrm{keV}$ from the plasma layer of the magnetotail. The bay in the absorption begins later at the northern stations than at southern ones, and this behavior is one of the typical features of substorms [Akasofu, 1971]. At the southernmost station of the meridional network PINA $\left(\varphi=50.20^{\circ}\right)$, no precipitation is recorded (Figure 9, $a$ ).

Let us examine the dynamics of the auroral electrojet from $\mathrm{H}$-component variations. Referring to Figure 9, $b$, the southernmost meridional station PINA near the local midnight (MLT=0:35) at the time marked with the vertical line records a sharp increase in the $H$ component, which coincides with a similar increase registered at low-latitude stations in the dayside hemisphere. This increase was caused by the magnetosphere compression, abrupt shift of the magnetopause, and amplification of Chapman-Ferraro surface currents at the magnetopause. After passing the leading DS front, the geomagnetic field gradually returns to the undisturbed level, as at other mid-latitude stations. However, at the station ISLL located to the north $\left(\varphi \approx 54^{\circ}\right)$, at $05: 15$ UT there is a decrease in the $H$ component (arrow). The beginning of the negative bay in the $H$ component, as well as the beginning of the bay in the absorption, shifts to the northern stations. The depth of the bay increases as it shifts northward with a maximum of $\sim 450 \mathrm{nT}$ at the FCHU station. A northward shift is also observed for the maximum amplitude of irregular pulsations (Figure 9, c). The same behavior of the drift of the maximum ampli- 
tude of irregular geomagnetic pulsations Pi1, typical for the substorm active phase, was found from observations at the Norilsk meridional network of stations [Parkhomov, Rakhmatulin, 1975].

The change in the direction of the equivalent ionospheric current over stations of the meridional network as SLD develops and the electrojet shifts to the north is clearly seen in Figure 10, a. This Figure presents fragments of maps of equivalent ionospheric current vectors, calculated by the method worked out in [Parkhomov et al., 2011], over stations whose magnetograms are given in Figure 9 at the moments corresponding to the vertical lines in Figure $10, b$. This Figure also shows variations in the SW proton density and IMF modulus $B$ (DS is denoted by a rectangle). It is apparent that before the disturbance at 05:07:00 UT currents over all the meridian stations flow to the east, and the maximum current flows over the northernmost station TALO. At the moment corresponding to the SW maximum dynamic pressure (05:12 UT) and maximum Chapman-Ferraro currents at the dayside magnetopause, the eastward currents are amplified synchronously over the meridian stations with a maximum value above the RANK station. The current over PINA holds its eastward direction during the entire disturbance caused by DS.

At 05:15 UT, the direction of the current over ISSL changes to the westerly direction, and at 05:22 UT the westward current over GILL is amplified (this moment coincides with the beginning of the negative bay in the $H$ component (arrow in Figure 9, b)).

At 05:24 UT, the maximum of the westward current moves to the latitude of the FCHU station, and at 05:30
UT it reaches the RANK station. Above PINA and TALO, the eastward current holds its direction. Thus, maps of equivalent ionospheric currents also show the dynamics of currents which is characteristic of substorm events.

Note that the beginning of the geomagnetic field dipolization in the geostationary orbit aboard GOES-8 can be identified at 05:25 UT (rectangle II in Figure 9), and the second dipolization interval is recorded at the maximum of the SLD active phase, i.e. the dipolization in the outer quasi-capture region occurs during SLD caused by the magnetosphere-DS interaction.

\section{DISCUSSION}

In [Zhou, Tsurutani, 2001, Zhou et al., 2009] based on long-term studies of the magnetospheric response to jumps of SW and IMF parameters, responses of various types have been identified which include substorms, pseudobreakups, intensification of polar auroras, stable magnetospheric convection, intervals of long-term highintensity $A E$ activity, magnetic storms, and storm activation. The response of each type is determined by a certain combination of parameters of external forcing and internal state of the magnetosphere.

Zhou et al. [2003] analyze several shock aurora events when the magnetosphere is subject to interplanetary shocks and pressure impulses from observations of auroras in the UVI range at the Polar satellite and electrons and protons at the FAST and DMSP satellites. Particularly noteworthy is the case of the impact of a $4 \mathrm{nPa}$ SW pressure jump on the magnetosphere, with the IMF positive vertical component on August 04, 1997.
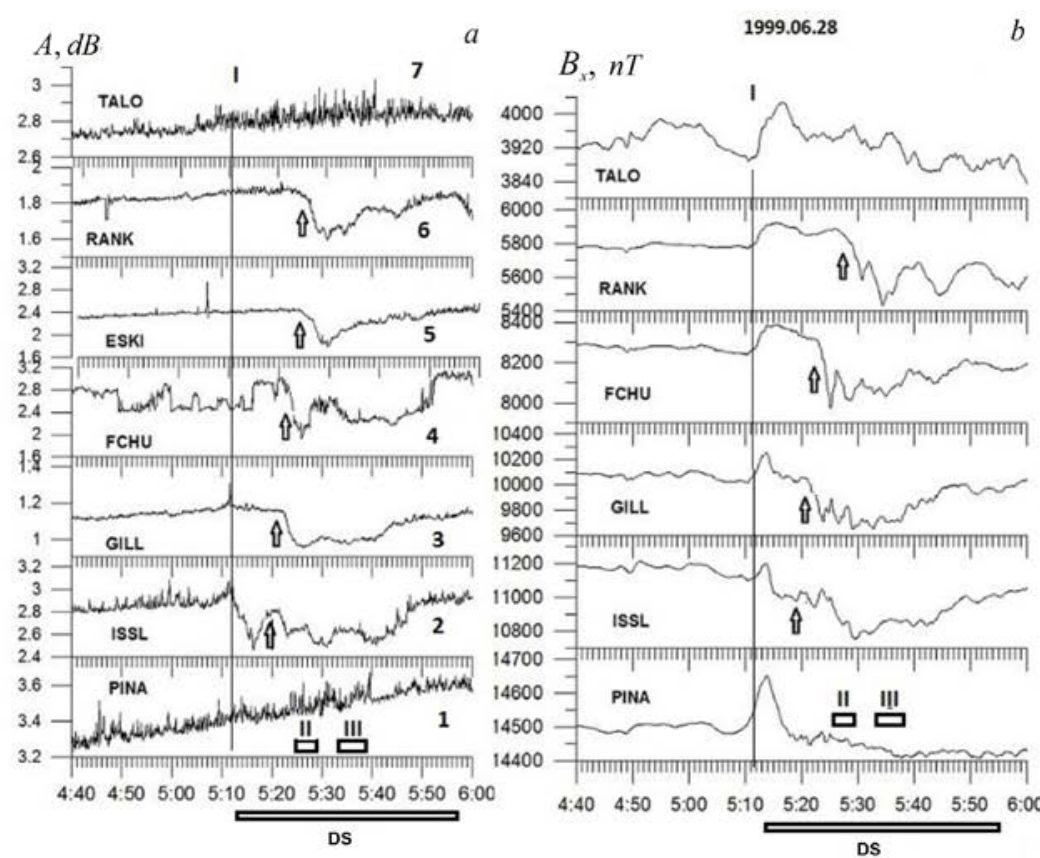

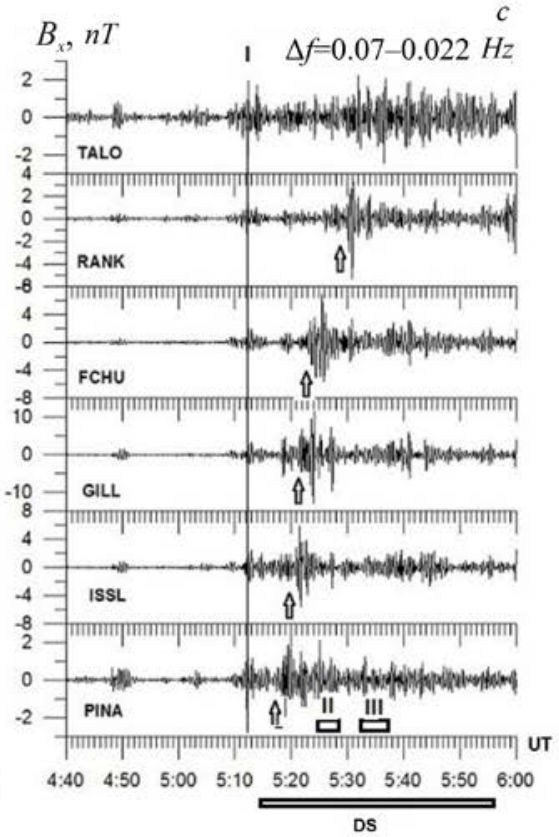

Figure 9. Geomagnetic response in the midnight meridian of the CANOPUS network (MLT $\sim 23-0^{\mathrm{hr}}$ ): variations in the auroral absorption intensity in a geographic latitude range $50.20^{\circ}-69.54^{\circ}$ (geomagnetic latitudes $61.15^{\circ}-79.65^{\circ}$ ) along the meridian at 23 MLT (a); $H$-component variations (b); variations in the intensity of geomagnetic pulsations in the Pi1 frequency range (15-45 s) (c). Solid thin line I indicates a sharp increase in the glow in the noon meridian. Arrows show the time of the beginning of the phenomenon at each station. The rectangle DS marks the time of observation of the diamagnetic structure. Rectangles II, III correspond to the intervals of dipolization in Figure 4, c. Numbers of the station correspond to Table 2 

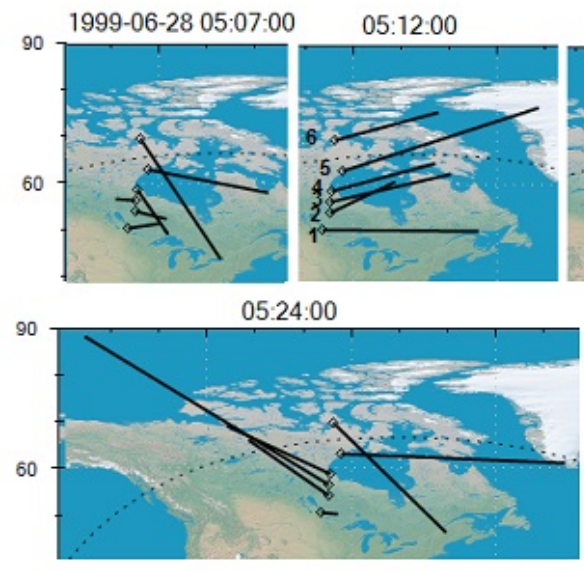

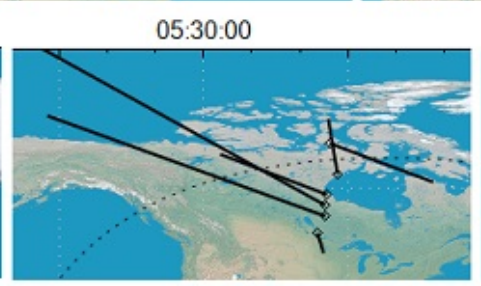

05:22:00
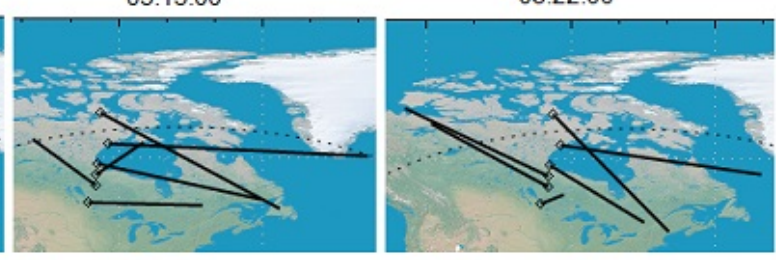

05:33:00

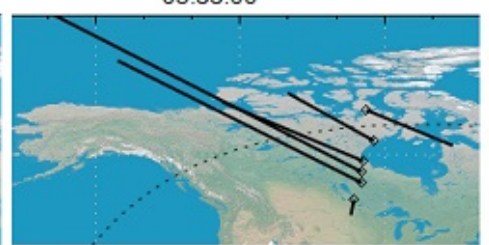

a)

a)

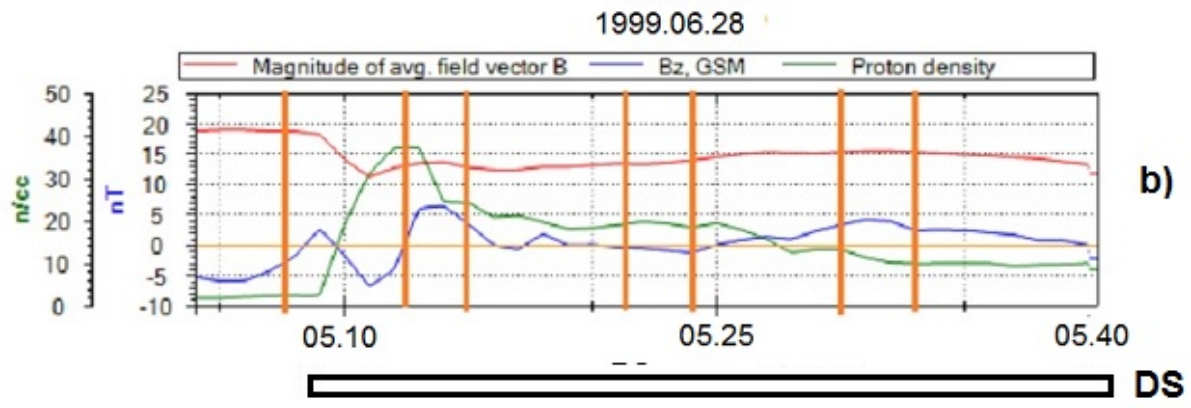

Figure 10. Fragments of maps of equivalent current vectors in the meridional network CANOPUS (MLT $\sim 23-0^{\mathrm{hr}}$ ), which demonstrate changes in the direction of the equivalent ionospheric current when the electrojet boundary moves northward during a substorm $(a)$; variations in IMF $\left(B_{\mathrm{av}}\right)$ and SW $\left(N_{\mathrm{p}}\right)$ parameters in the interval of interest $(b)$. Vertical lines show the time for which the maps of vectors are drawn. Station numbers are indicated in accordance with Table 2

As can be seen in Figure 4 from the article [Zhou et al., 2009] and follows from its description, the auroras began in the noon meridian and spread to the nightside.

According to results [Zhou et al., 2009] at 02:36:53 UT, aurora brightnenings enhanced in the noon sector and on the morning side. At 02:39:57 UT, a 2 kR auroral brightening was in the 09:00-12:00 MLT sector between $72^{\circ}$ and $80^{\circ}$ geomagnetic latitudes. Auroras near the local midday spread to low latitudes to the $65^{\circ}$ geomagnetic latitude. This agrees with the results obtained in [Liou et al., 2002] on noon auroras caused by interplanetary shocks. The auroral intensity was $1 \mathrm{kR}$ in the sector from $65^{\circ}$ to $73^{\circ}$ geomagnetic latitude and then sharply decreased at 02:43:01. The auroral intensity at the near-polar boundary of the morning side of the polar oval was 1.3-1.8 kR. On the evening side, the auroral intensity increased then and the brightening spread to the nightside of the oval, as indicated by the following two images taken at 02:46:05 and 02:49:09" (our italics).

If we consider variations in the SW proton density and IMF modulus $B$ in the interval 02:30-03:05 UT on August 04, 1997, we can interpret them as features of DS being a part of CME. In this interval, the SW proton density and IMF modulus change in antiphase: the correlation coefficient $R\left(B, N_{\mathrm{p}}\right) \approx-0.3$.

An additional argument for our conclusion is the analogy of current systems on June 28, 1999 (Figure 11) and August 04, 1997 (Figure 12), arising from the development of SLD. The maps of vectors of equivalent ionospheric currents show that in both the events a current system DP-2 with a powerful westward current appears on the nightside (for both the events the maps are drawn for a moment of $17 \mathrm{~min}$ after the magnetopause-DS interaction).

Another confirmation of the above assumptions can be found in [Tagirov et al., 1998], where two substorms of December 09, 1996, which followed one after another with an interval of one hour and differed significantly in sources, have been studied. The beginning of the former is clearly related to the magnetosphere-DS interaction with the IMF northward vertical component. For this structure, according to our calculations, $R(B$, $\left.N_{\mathrm{p}}\right)=-0.91 \pm 0.02$. The substorm is classified by Tagirov et al. [1998] as pseudobreakup. For our research, an important point is that this magnetospheric disturbance was caused by DS. The latter (classical) substorm did not have explicit external triggers, but it began after a long existence $(\sim 1 \mathrm{hr})$ of southward IMF before SW with a high pressure area approached the magnetosphere.

Huttunen et al. [2002] have examined substorm-like events during a strong magnetic storm. They have concluded that under the SW conditions considered, the amplification of the auroral electrojet as part of substorm activation is directly determined by IMF and SW parameters rather than dynamic processes in the magnetotail. 

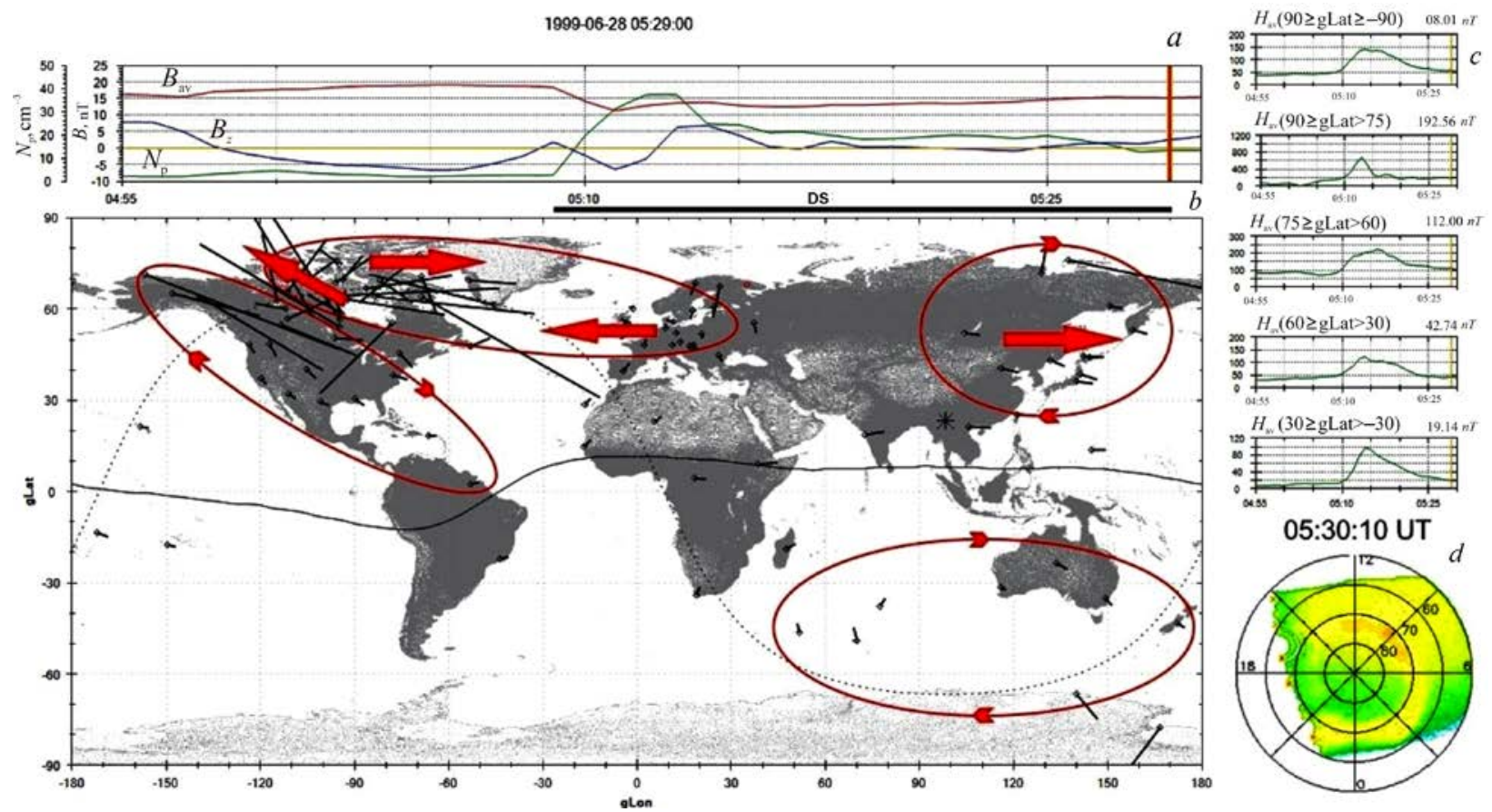

Figure 11. SLD on June 28, 1999: variations in SW proton density and IMF vertical component modulus (a); a map of vectors of equivalent ionospheric currents for 18:30 UT (b); variations in the average geomagnetic field strength induced by the equivalent ionospheric current in given latitudinal intervals (c); an auroral image from the Polar satellite (d). The dotted line denotes the terminator line, the solid line represents the magnetic equator, the asterisk indicates the position of the subsolar point, arrows show the preferred direction of ionospheric currents. The DS horizontal line is the DS observation time, the vertical line is the time of calculation of parameters. $H_{\mathrm{av}}$ is the average geomagnetic field strength produced by an equivalent ionospheric current in a given latitude range $(c)$. In the upper right-hand corner $(c)$ is the geomagnetic field strength average over the observatories in a given latitude range at the time indicated by the vertical line

It has been found that the intervals in SW in which the SW density variations in antiphase with IMF modulus variations cause a synchronous response in geophysical phenomena observed on Earth, in the Polar orbit, in the geosynchronous orbit, and in the plasma layer of the magnetotail. The SW pressure rise with weakly negative $B_{z}$ whose amplitude increases at the time of the rise can not only trigger a substorm, but also determine the release of energy coming from SW.

A similar model of the impact of SW pressure rise has been described in [Zhou et al., 2013]. According to the model, DS propagating at a high velocity in SW along the magnetotail compresses the tail. This leads to energy transfer to the plasma layer and to the development of processes analogous to those occurring during the classical substorm. Subsequent to the magnetotail compression to $80 \%$ [Zhou et al., 2013], there emerge earthward plasma streams and dipolization fronts similar to those shown in Figure 4, c. These phenomena cause processes in the auroral zone similar to auroral substorms.

The time of SLD activation depends on spatial dimensions of a filament (DS). In the June 28, 1999 event, $\sim 5$ min (05:19 UT, arrows in Figure 9, $a-c)$ passed from the moment of the magnetosphere-DS interaction (05:11:40 UT), determined from the highest brightness of auroras in the UVI range in the noon meridian (Figure 9, b), to the intensification of precipitation and auroral electrojet of SLD in the midnight meridian. The same delay time for the intensification of auroras on the nightside has also been found for the August 04, 1997 event in [Zhou et al., 2003]. In Figure 10 , the vector of the equivalent current over ISLL changes its direction at 05:15 UT; therefore we can take 05:17 UT as the average time of the SLD onset.

In the event we analyze, the source of energy of the powerful SLD with $A E_{\max }=1280 \mathrm{nT}$ was DS in the SW stream after a long period of existence of northward $B_{z}$. The energy of this structure was dissipated in the processes comprising the SLD, without being previously accumulated in the magnetotail.

One final comment is that, despite the abundance of publications on the problem we address, it is far from clear understanding due to the variety of SW inhomogeneities and many degrees of freedom of magnetospheric conditions. Therefore, it is very difficult to uniquely identify the magnetospheric response to IMF reversal or pressure rise. They often work together and generate SLD, as in the event considered.

\section{MAIN RESULTS}

The data analysis has revealed not only qualitative similarity, but also some differences in the onset, development, and decay of the examined magnetospheric disturbances caused by different energy sources - reconnection of IMF and magnetospheric field lines in the first substorm and the magnetosphere-DS interaction in SLD. The main differences in the dynamics of the two geomagnetic disturbances considered are as follows. 

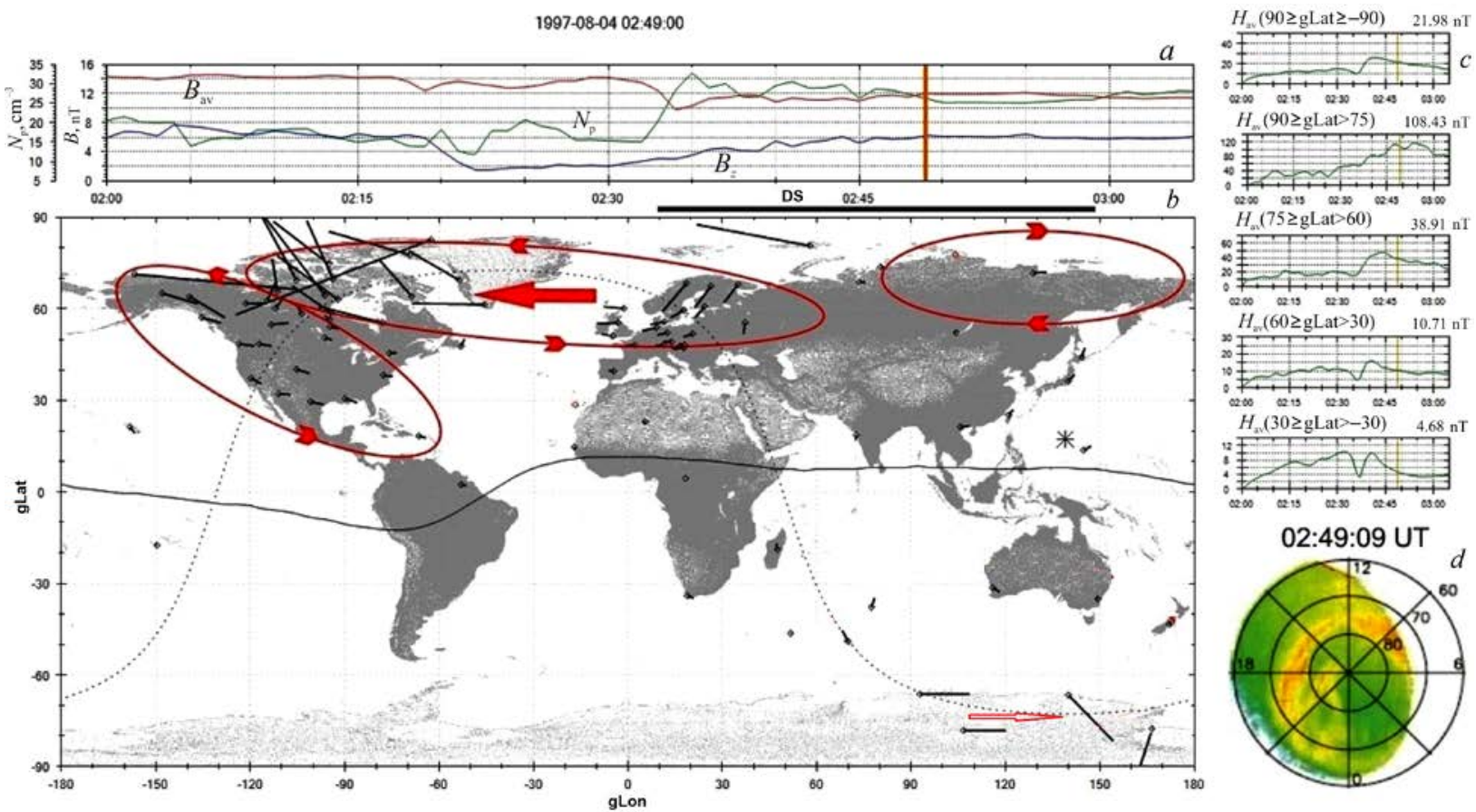

Figure 12. The same as in Figure 11 for the August 04, 1997 SLD. The map of vectors of equivalent ionospheric currents is given for 18:20 UT $(b)$

1. The classical substorm (Figure 5, interval II) occurred after the long existence of the southward $B_{z}$, began spontaneously, without apparent abrupt changes in SW and IMF. The maximum intensity of the substorm was $A E=1350 \mathrm{nT}$. The picture of the development of auroras, as derived from Polar satellite observations, and auroral absorption, according to data from the meridional network of riometers, corresponds to the dynamics of the development of the auroral substorm [Akasofu, 1971]. The substorm from the activation phase to the recovery phase lasted for $\sim 2$ hrs.

2. In interval III (Figure 5) there was a magnetospheric disturbance the source of which was SW DS and which occurred after a long existence ( $~ 5 \mathrm{hrs}$ ) of the IMF northward vertical component. The maximum intensity of the disturbance $A E=1262 \mathrm{nT}$ is comparable with the $A E$ index of the classical substorm. According to geomagnetic variations in the outer quasi-capture (dipolization) region, the dynamics of auroral absorption, ionospheric current systems, and the drift of the source of irregular geomagnetic pulsations in the midnight meridian, the observed disturbance can be classified as a substorm. The assumption that the disturbance contains elements inherent to substorms is confirmed by the data presented in Figures $8, b-c, 9, a, b$, and 10, which show the beginning of the development of the SLD after the magnetosphere-DS interaction (Figure 10) and the appearance of a homogeneous arc of aurora on the noon side in the UVI range at the daytime cusp latitudes with its subsequent sharp brightening and motion of the aurora fronts to the west and east of the noon meridian (Figure 8, b, c). This disturbance lasted for $\sim 50 \mathrm{~min}$.

3 . Founding on the dynamics and the time of development of SLD, we can distinguish four phases of the disturbance, similar to those of the classical substorm: growth, explosive, active, and recovery. The growth phase lasts from the beginning of the magnetosphereDS interaction to the beginning of the movement of the western and eastern fronts of auroras (05:00-05:11 UT), breakup (05:12-05:18 UT), active (05:18-05:32 UT) and recovery (05: 32-06: 12 UT) phases.

We are grateful to G.V. Rudenko for calculating positions of footpoints of open magnetic flux tubes of the coronal hole and neutral line of the Sun's global magnetic field, D.G. Baishev for consultations and useful discussions.

We gratefully acknowledge NASA CDAWEB for providing data from the ACE, IMP-8, Wind, Geotail, Polar, GOES-8, and GOES-10 satellites. We are thankful to the Canadian Space Science Data Portal, J. Mann, D.K. Milling and members of the CARISMA team. We thank the Kyoto World Data Center for Geomagnetism and the Intermagnet network for providing access to geomagnetic data used therein.

The work was partially supported by RFBR grant 16-02-00669 and grant NSC103-2923-M-006-002MY3/14-05-92002HHC Taiwan-RFBR.

\section{REFERENCES}

Akasofu S.I. Polar and Magnetosheric Substorms. Moscow, Mir, 1971, 320 p. (In Russian). English edition: Akasofu S.I. Polar and Magnetosheric Substorms. New York, SpringerVerlag, 1968, 280 p.

Borodkova N.L. Effect of large-scale wind pressure on the Earths's magnetosphere: analysis of several events. Cosmic Reseach. 2010, vol. 48, no. 1, pp. 41-55. DOI: 10.1134/ S001095251001003X.

Eselevich V.G., Eselevich M.V. Fractal structure of the heliospheric plasma layer on the Earth's orbit. Geomagnetizm $i$ aeronomiya [Geomagnetism and Aeronomy]. 2005, vol. 45, no. 3, p. 347. (In Russian). 
Eselevich M.V., Eselevich V.G., Fujiki K. Streamer belt and chains as the main sources of quasi-stationary slow solar wind. Solar Phys . 2007, vol. 240, p. 135.

Eselevich V.G., Fainshtein V.G., Rudenko G.V. Study of the structure of streamer belts and chains in the solar corona. Solar Phys. 1999, vol. 188, no. 2, p. 277.

Eselevich V.G., Fainshtein V.G., Rudenko G.V., Eselevich M.V., Kashapova L.K. Forecasting the velocity of a quasi-stationary solar wind and the intensity of geomagnetic disturbances produced by it. Cosmic. Res. 2009, vol. 47, no. 2 , pp. 95-113.

Huttunen K.E.J., Koskinen H.E.J., Pulkkinen T.I., Pulkkinen A., Palmroth M., Reeves E.G.D., Singer H.J. April 2000 magnetic storm: Solar wind driver and magnetospheric response. J. Geophys. Res. 2002, vol. 107, no. A12, 1440. DOI: 10.1029/2001JA009154.

Lin R.L., Zhang X.X., Liu S.Q., Wang Y.L., Gong J.C. A three-dimensional asymmetric magnetopause model. J. Geophys. Res. 2010, vol. 115, A04207. DOI: 10.1029/2009JA014235.

Liou K., Wu C.-C., Lepping R.P., Newell P.T., Meng C.-I. Midday subauroral patches (MSPs) associated with interplanetary shocks. Geophys. Res. Lett. 2002, vol. 29, no. 16, p. 1771. DOI: $10.1029 / 2001 G L 014182$.

Lui A.T.Y. Current controversies in magnetospheric physics. Rev. Geophys. 2001, vol. 39, pp. 535-564.

O’Brien T.P., McPherron R.L. Seasonal and diurnal variation of Dst dynamics. J. Geophys. Res. 2002, vol. 107, no. A11. DOI: $\underline{10.1029 / 2002 J A 009435}$

Parkhomov V.A., Rakhmatulin R.A. Localization and latitudinal drift of the source Pi1B. Issledovaniya po geomagnetizmu, aeronomii i fizike Solntsa [Reseach on Geomagnetism, Aeronomy, and Solar Physics]. Moscow, Nauka Publ., 1975, iss. 6, p. 132. (In Russian)

Parkhomov V.A., Borodkova N.L., Dmitriev A.V., Klimov P.M., Rakhmatulin R.A. The role of solar wind pressure in the initiation and control processes of magnetospheric substorms. Geomagnetism and Aeronomy. 2011, vol. 51, no. 7, pp. 979-993. DOI: https://doi.org/10.1134/S0016793211070176.

Parkhomov V.A., Borodkova N.L., Eselevich V.G., Eselevich M.V. Abrupt changes of density in sporadic solar wind and their effect on Earth magnetosphere. Cosmic Res. 2015 , vol. 53, no. 6, pp. 411-422. DOI: 10.1134/S0010952515050093.

Rouillard A.P., Sheeley N.R. Jr., Cooper T.J., Davies J.A., Lavraud B., Kilpua E.K.J., Skoug R.M., Steinberg J.T., Szabo A., Opitz A., Sauvaud J.-A. The solar original of small interplanetary transients. Astrophys. J. 2011, vol. 734, 10 p. DOI: 10.1088/0004-637X/734/1/7.

Schwenn R., Dal Lago A., Huttunen E., Gonzalez W.D. The association of coronal mass ejections with their effects near the Earth. Annales Geophysicae. 2005, vol. 23, pp. 1033-1059.

Sergeev V., Nishimura Y., Kubyshkina M., Angelopoulos V., Nakamura R., Singer H. Magnetospheric location of the equatorward prebreakup arc. J. Geophys. Res. 2012, vol. 117, A01212. DOI: 10.1029/2011JA017154.

Storm Sudden Commencements (SSC). International service on rapid magnetic variations. URL: http://www.obsebre.es/ en/rapid (accessed April 26, 2017).

Svalgaard L.J., Wilcox W., Duvall T.L. A model combining the solar magnetic field. Solar Phys. 1974, vol. 37, p. 157.

Tagirov V.R., Arinin V.A., Meng C.I., Sibeck D.G., Lui A.T.Y., Liou K., Ivanov A.G., Frank L.A., Morgan D., Parks G. Comparison of two substorm onsets on the basis of coordinated ground-satellite observations. Fourth International Conference on Substorms (ICS-4). 1998, pp. 339-342.

Torr M.R., Torr D.G., Zukic M., Johnson R.B., Ajello J., Banks P., Clark K., Cole K., Keffer C., Parks G., Tsurutani B., Spann J. A far ultraviolet imager for the International SolarTerrestrial Physics Mission. Space Sci. Rev. 1995, vol. 71, iss. 1-4, pp. 329-383.
Wang Y.M., Sheeley N.R., Rich N.B. Coronal pseudostreamers. Astrophys. J. 2007, vol. 685, p. 1340.

Zhou X., Tsurutani B.T. Rapid intensification and propagation of the dayside aurora: large scale interplanetary pressure pulses (fast shocks). Geophys. Res. Lett. 1999, vol. 26, no. 8, pp. 1097-1100. DOI: 10.1029/1999GL900173.

Zhou X., Tsurutani B.T. Interplanetary shock triggering of nightside geomagnetic activity: substorms, pseudobreakups and quiescent events. J. Geophys. Res. 2001, vol. 106, no. A9, pp. 18,957-18,967. DOI: 10.1029/2000JA003028.

Zhou X.-Y., Strangeway R.J., Anderson P.C., Sibeck D.G., Tsurutani B.T., Haerende G., Frey H.U., Arballo J.K. Shock aurora: FAST and DMSP observations. J. Geophys. Res. 2003, vol. 108, no. A4, p. 8019. DOI: 10.1029/2002JA009701.

Zhou X.-Y., Fukui K., Carlson H.C., Moen J.I., Strangeway R.J. Shock aurora: ground-based imager observations. J. Geophys. Res. 2009, vol. 114, A12216. DOI: 10.1029/ 2009JA014186.

Zhou X.-Y., Zhou X.-Z., Angelopolus V., Shi Q., Wang C.-P., Frey $\mathrm{H}$. Interplanetary shock-induced current sheet disturbances leading to auroral activations: THEMIS observations. J. Geophys. Res. 2013, vol. 118, p. 3173. DOI: 10.1002/jgra.50175.

URL: http://cdaweb.gsfc. nasa.gov/cgi-bin/eval2.cgi (accessed April 26, 2017).

URL: http://bdm.iszf.irk.ru (accessed April 26, 2017). 2017).

URL: http://cdaw.gsfc.nasa.gov/CME_list (accessed April 26, 2017).

URL: http://www.obsebre.es/en/rapid (accessed April 26,

URL: http://cdaweb.sci.gsfc. nasa.gov/cdaweb/istp_public (accessed April 26, 2017).

URL: http://aurora.phys.ucalgary.ca/cgi-bin/rio (accessed April 26, 2017).

Color drawings are available in the electronic version of the article.

How to cite this article

Parkhov V.A., Borodkova N.L., Eselevich V.G., Eselevich M.V., Dmitriev A.V., Chilikin V.E.. Features of the impact of the solar wind diamagnetic structure on Earth's magnetosphere. Solar-Terrestrial Physics. 2017. Vol. 3, No. 4, P. 44-57. DOI: $10.12737 /$ stp-34201705 